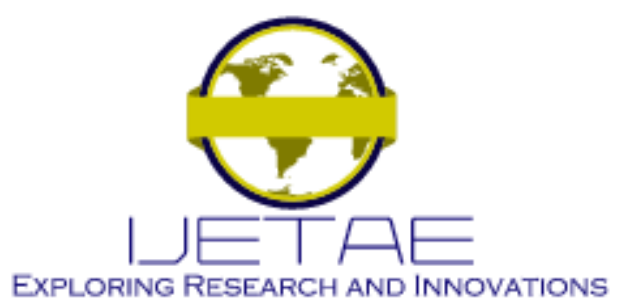

International Journal of Emerging Technology and Advanced Engineering

Website: www.ijetae.com (E-ISSN 2250-2459, Scopus Indexed, ISO 9001:2008 Certified Journal, Volume 12, Issue 02, February 2022)

\title{
Improved Accuracy of Animal Skin Pattern retrieval with CNN Model and Distance Metrics
}

\author{
Ayu Hidayah Aslamiah ${ }^{1}$, Abdul Haris Rangkuti ${ }^{2}$, Ayuliana $^{3}$, Varyl Hasbi Athala ${ }^{4}$, Naufal Fauzi Lutffi ${ }^{5}$, \\ Syaugi Vikri Aditama ${ }^{6}$ \\ 1,2,3,4,5,6 Informatics Department, School of Computer Science, Bina Nusantara University, Jakarta, Indonesia 11480 \\ ${ }^{1}$ ayu.aslamia001@binus.ac.id, ${ }^{2}$ rangku2000@binus.ac.id, ${ }^{3}$ Ayuliana st@binus.ac, id, \\ ${ }^{4}$ varyl.athala@binus.ac.id, ${ }^{5}$ aufal. luthfi@binus.ac.id, ${ }^{6}$ syaugi.aditama@binus.ac.id
}

\begin{abstract}
This study describes the retrieval of animal skins with very diverse shapes and textures. With so many variations in each animal skin pattern, an appropriate and supported CNN model is needed as well as an appropriate distance matrix method to support retrieval performance. This research was conducted on 6 types of animal skin images. In experimenting to obtain this animal skin image, $4 \mathrm{CNN}$ models were used, namely EfficientnetB7, Inception V3, MobilenetV2, and Resnet50 V2, as well as 2 distance metrics methods, namely Euclidean and Manhattan. Based on the experiment, the average with 2 measuring distances is more than $90 \%$. The CNN model has the highest retrieval accuracy in Inception V3 with an average of $97.2 \%$ MobilenetV2 with an average of $92.9 \%$, Resnet50 V2 with an average of $95.5 \%$, and EfficientNetB7 with an average of $96 \%$. In the skin animal image retrieval accuracy which is more than $70 \%$, the highest number on CNN model Inception V2 is 41 images and EfficientNetb7 is 40 images with Manhattan Distance. Some animal skin image patterns have a retrieval accuracy of up to $100 \%$ using $4 \mathrm{CNN}$ models, but some patterns have an accuracy below 50\%, so this is part of the continuation of research on animal skin patterns.
\end{abstract}

Keywords-- Manhattan, Euclidean, CNN, EfficientnetB7, InceptionV3, Mobilenet V2, Resnet50 V2

\section{INTRODUCTION}

Basically in Indonesia, a lot of animal skins are used as the main material in the leather industry and works of art. Currently, leather is widely used as a raw material for the manufacture of clothing, vehicle interiors, furniture, shoes, accessories and other necessities[1]. Using leather will be the right choice because it offers comfort and durability. The leather material used and will be used for the process of making goods has several types. This type has different textures according to needs [2].
During the process of processing animal skins into genuine leather, the animal skins have undergone changes in both texture and color. This makes it difficult to know the type of animal skin that comes from one species to another, for example cow, crocodile, snake and pig skin [3].

This research focuses on supporting the retrieval process of Skin Animal image that have a variety of characteristics, both in terms of texture, shape and color. To get optimal results, this study uses several Convolutional Neural Network models such as Inception V3, VGG 19 and efficientnetB8. However, to increase the accuracy of the output, preprocessing will be carried out to reduce image noise and process resizing, optimizing, and normalizing the image database. To do the image retrieval, processed images need to get extracted into feature vectors. Based on reference, feature vectors of query images are constructed the same way as features vectors of image database. That way, feature vectors could be measured based on similarity using distance metrics like Euclidean distance[7].

These processes are combined to form this research on Content-Based Image Retrieval with the expectation to improve this system to gain good output results on skin Animal image. The tools used in animal skin image processing are supported by hardware that is supported by advanced GPU and Processor hardware up to I9. With this tool can support the compilation process of data training. To get the characteristics of animal skins optimally, apart from being supported by the latest hardware technology such as processors and memory, both high RAM and VRAM, it is also supported by the right programming language in image processing. Like Python, which supports the convolutional neural network model in carrying out several experiments to produce maximum retrieval accuracy performance. 


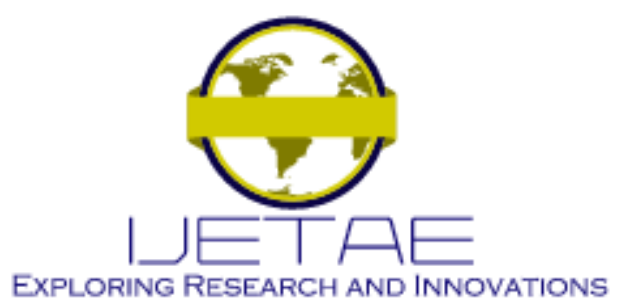

\section{International Journal of Emerging Technology and Advanced Engineering}

Website: www.ijetae.com (E-ISSN 2250-2459, Scopus Indexed, ISO 9001:2008 Certified Journal, Volume 12, Issue 02, February 2022)

\section{RELATED STUDY}

Based on this observations made at the Cibaduyut leather center in Bandung, some leather sellers do not know the type of leather they use to make goods such as shoes, leather shirts, and even drums. This is due to a lack of knowledge about leather materials resulting in the wrong in buying the desired leather material [4]. In addition, with a valid source of knowledge, it will be able to explain the type of leather material and its quality. Some of these types of leather include full grain leather, milling leather, nappa leather, patent leather, buck/unbuck leather, suede leather, and pull up leather[5]. Based on this, identification of leather type materials is needed for those who have the need to know certain leather types so that consumers can use leather appropriately. In some types of animal skin has difficulty to be observed visually. [6].

However, everyone don't realize the difference between the skin types of these animals. To overcome these problems, we need a system that can identify the type of animal skin material. For research on animal skin images, the focus will be on examining the texture characteristic[7]. It is hoped that by knowing the texture characteristics of animal skins, it is possible to know whether it is genuine cowhide or fake, and even cowhide, goatskin, crocodile skin, snakeskin and pigskin. Leather product manufacturing technology is a method or technique of making ready-touse goods by using media or materials derived from leather into products that have added value[8].

In order to avoid the cheat, buyers must know the design of leather texture to recognize the type of skin the leather made of. To aid the matter, this paper aims to classify four types of animal skin that used for leather products i.e. pig, cattle, elephant, and synthetic material. Backpropagation Neural Network (BPNN) is applied to the data to automatically classify the image into their classes and The result with classification rate achieved above $85 \%$ at universal condition of digital image captured[9]. Another study of content-based image retrieval was done on retrieving images using wavelet transforms like haar for texture feature extraction, color moment for color feature extraction, or both method. Canberra distance was used to calculate feature vectors between query image and database. Based on reference, this study found that using Haar wavelet resulted in $71.25 \%$, color moment at $77.0 \%$, and both methods at $88 \%$. This means that using both method increases retrieval efficiency on all datasets[10].

In animal skin image research, it has its own difficulties when classification and retrieval are carried out. Several CNN models are used to support the retrieval process of animal skin images.
The technology used to support the process of retrieving animal skin images can be seen in Figure 1.0.

\section{RESEARCH METHODOLOGY}

In research on animal skin image retrieval, the stages can be seen in diagram 1.0.

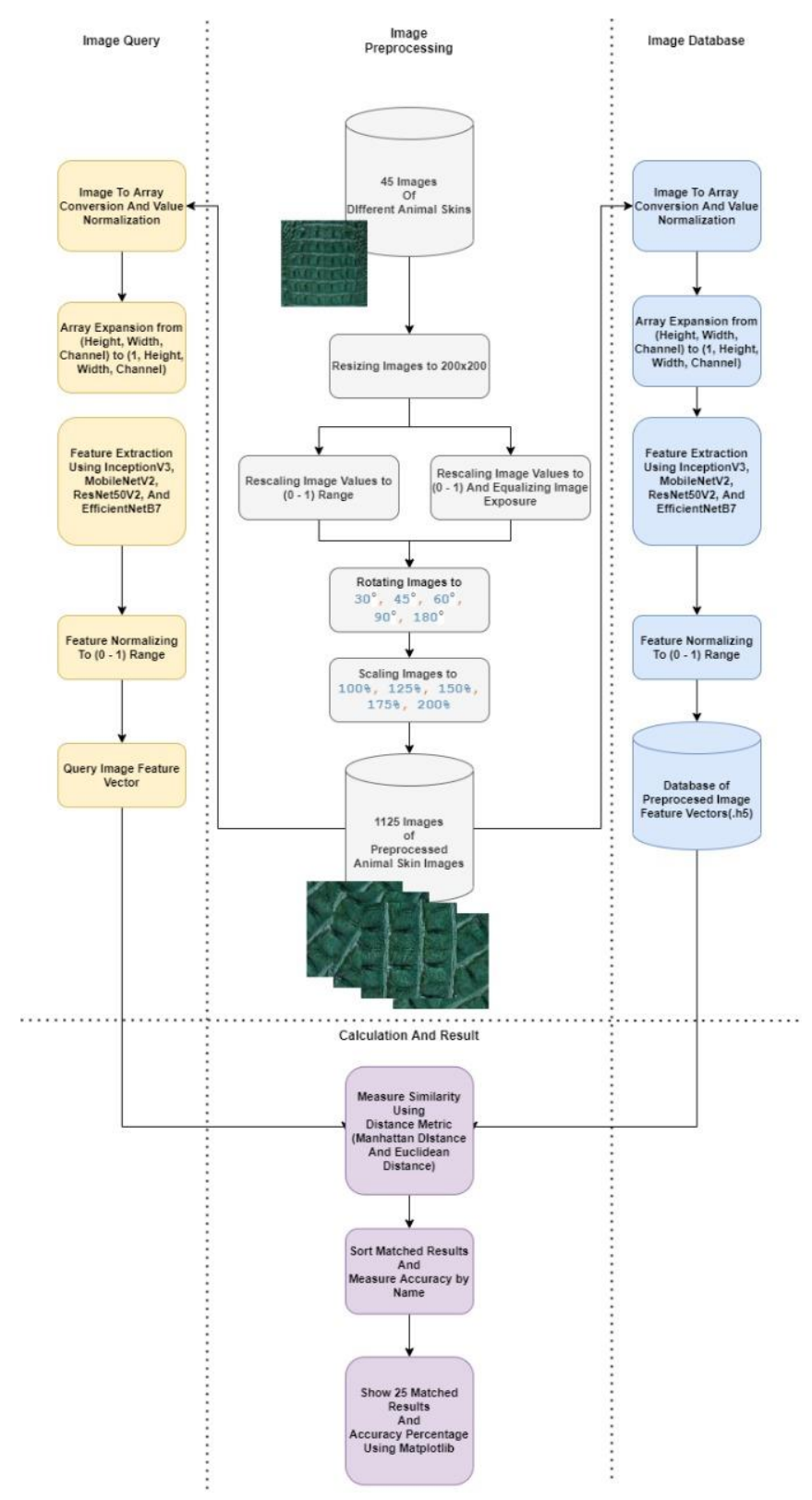

Figure 1.0 : Research diagram study of "Image Retrieval of Skin Animal Image Using CNN" 


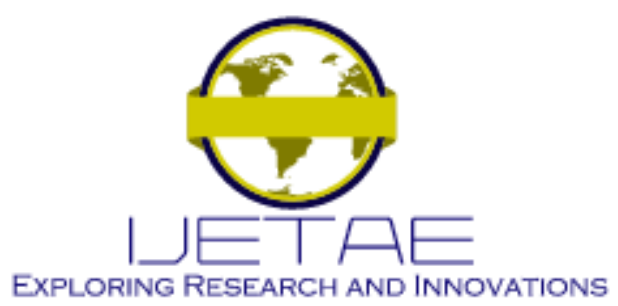

International Journal of Emerging Technology and Advanced Engineering

Website: www.ijetae.com (E-ISSN 2250-2459, Scopus Indexed, ISO 9001:2008 Certified Journal, Volume 12, Issue 02, February 2022)

The process starts in collecting Animal Skin Image from the internet and ends with showing the results. As of Figure 1.0 , there are 4 different colors which are white, red, blue, and purple. Each color indicates a different process. The white-colored indicate preprocessing state. The red-colored and blue-colored indicate feature extraction. But the difference between these two is that the red one indicates the image database as input while the blue one indicates the sample image from the database (Query Image) as input. And finally, the purple-colored indicates calculation and showing the output. Therefore, these are the main processes of this study:

\section{A. Preparing Skin Animal Image}

Before starting this research, images of Animal Skin must be collected. These images are mostly taken from the internet. All collected images are mostly in the format of .jpg and .png. These images are good enough in terms of brightness, contrast, noise, obstruction to make sure optimum result later. Images that are taken from the internet mostly had irregular image ratios. It is required to have a 1:1 ratio to extract features using CNN[10]. Therefore, every image must be manually resized to a fixed 1:1 image ratio. Based on reference, resizing images to fixed size is required due to the strict requirement of the CNN. This is to prevent the image from being unintentionally stretched which decreases the Animal Skin pattern authenticity and output accuracy. Last, images are name formatted into 2 letters followed by a number. In this case, letters indicate the name and a number indicates cloth variant. This was done to make the identification of the image much easier. Collection of Skin Animal Images in Figure 2.0.

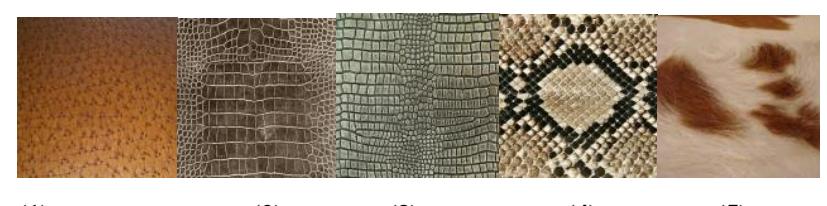

(1)

(2)

(3)

(4)

(5)

Figure 2.0 : Resized collected animal skin images 1.Babi 2.Crocodile 3. Lion, 4.Snack, 5.Shep

\section{B. Dataset Setup}

In this study, there were 45 different animal skin images collected randomly from internet technology. The skin image data collection method consists of 9 classes based on animal names.
Each class contains up to 5 Animal Skins with different patterns. For each animal skin pattern, it will experience a rotation change of $30,45,60,90,180$ degrees, then each image after undergoing rotation is continued with a scale change of 100,125, 150,175, 200\% of the original image. So that the total images of animal skins studied were 1125 images.

\section{Extracting Features Using CNN}

In this research, features extraction is a process of extracting characteristics or features from an image. distance metrics also play role in most cases of image retrieval studies. Another study uses several CNN models such as research on traditional clothes patterns that have been carried out. Inception V3 is a type of deep learning convolutional neural network that has a very high level of accuracy in classifying[11].

The other CNNs that were used are EfficientNetB7 and InceptionV3. In a CNN, there are three main layers which are Convolutional, Pooling, and Fully Connected Layer. But in the case of image retrieval, the fully connected layer is important because this layer is a multilayer perceptron (MLP) which is a part of an artificial neural network (ANN) with neurons that are linked by connecting weight. Different CNN means different amount of features that can be extracted[12]. In VGG19, each about 4096 features get extracted out of an image. These extracted features are what the feature vectors of this study become. Before extracting features, all the images must be converted into an array type and preprocessed into a certain range depends on the model. Once converted and preprocessed, extraction features using CNN can be started. All the feature vectors also must be normalized to make the feature vectors range from 0 to 1 . This is done to reduce the extremities of feature vectors[13].

\section{Measuring Images Distance}

Measuring Images Distance is a process of measuring the distance between two points of feature vectors. In this study, there are two types of Distance Metrics that were used namely Manhattan Distance and Euclidean Distance. However, the basic formula for the Distance Metrics is a derivative of the Minkowski formula as follow: Given two simple feature vectors $\mathrm{X}=\left[\begin{array}{lll}\mathrm{x}_{1} & \ldots & \mathrm{x}_{\mathrm{n}}\end{array}\right]$ and $\mathrm{Y}=\left[\begin{array}{lll}\mathrm{y}_{1} & \ldots & \mathrm{y}_{\mathrm{n}}\end{array}\right]$

$$
\Delta \mathrm{d}=\left(\sum_{i=1}^{n}\left|x_{i}-y_{i}\right|^{p}\right)^{\frac{1}{p}}
$$




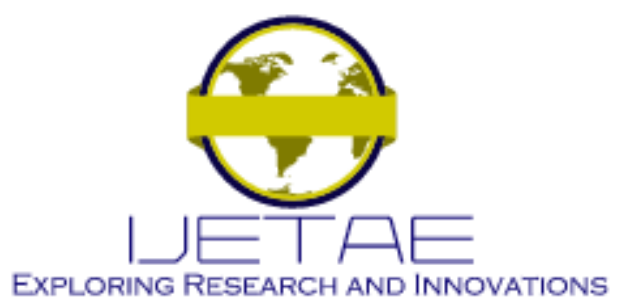

International Journal of Emerging Technology and Advanced Engineering

Website: www.ijetae.com (E-ISSN 2250-2459, Scopus Indexed, ISO 9001:2008 Certified Journal, Volume 12, Issue 02, February 2022)

Where:

$\mathrm{x}=$ feature vector component 1

$\mathrm{y}=$ feature vector component 2

$\mathrm{n}=$ the amount of feature vectors component

$\mathrm{p}=$ distance order

$\mathrm{i}=$ feature vector component number.

The smaller the distance, the higher similarity between the two feature vectors. To measure between image database with $(4144,4096)$ and query image with $(1,4096)$ each image feature vector in the image database is calculated to query image. The output is saved in an array that consists of distance similarity and the name for each image.

\section{E. Sorting and Showing Output}

Next, we carry out the process of sorting the findings back after the previous one. The feature extraction process needed to support the image retrieval process has been carried out. By sorting animal skin images, it will get a sequence of animal skin images with the highest to lowest accuracy. In this research, indirect sort is used to get the features of the vector image database. As we mentioned earlier, small distance means high similarity. Therefore, sorting from the lowest to the highest distance is the solution to this problem [14]. In a topic of calculating accuracy, it can be calculated using a simple equation. The following equation can be used to calculate accuracy:

Acc $=\frac{\text { Total Relevant Images }}{\text { Amount of identical Images } * 100 \%}$

There are also things to note:

$>$ Total Relevant Images means the amount of all the images that have the same pattern

$>$ Amount of identical images is the amount of images created after preprocessing per image.

\section{RESULT AND ANALYSIS}

\section{A. Result}

In this study, for retrieval using 2 ways for segmentation, namely with RGB and RGB+ Equalized. By using this segmentation approach to support the extraction of animal skin image features so as to optimize the performance of animal skin image retrieval. In the retrieval experiment, the feature extraction process used $4 \mathrm{CNN}$ models, namely Inception V3, Resnet50V2, Mobile net V2, and EfficientnetB7 to get the average value of retrieval accuracy. The results can be seen in Figure 3.0

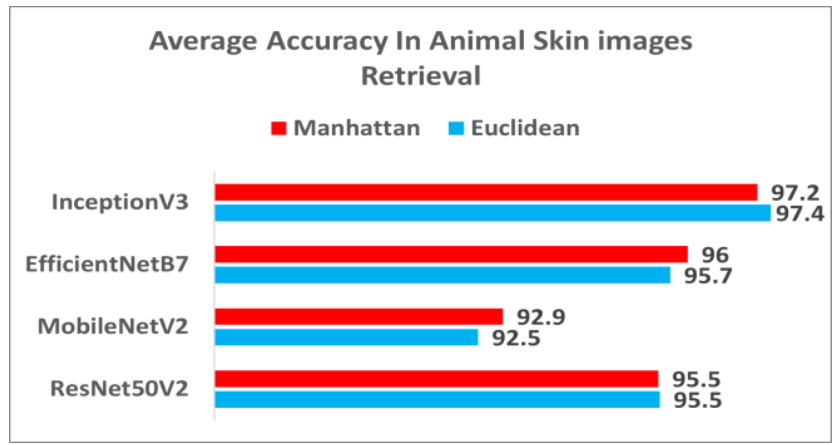

Figure 3.0: Average accuracy of animal skin image retrieval using 4 CNN models

In Figure 3.0, the highest accuracy results in retrieval on animal skin images using the CNN model are Inception V3 with the Manhattan method of $97.2 \%$, while Euclidean is 97.4\%. For the EfficientNetB7 model, the Manhattan method is $96 \%$ while the Euclidean method is $95.7 \%$. For the Mobilenet V2 model, the Manhattan method is $92.9 \%$ while the Euclidean method is $92.5 \%$. Resnet 50V2 model with Manhattan method is $95.5 \%$ while Euclidean is $95.5 \%$. Based on this description, it can be concluded that the highest accuracy is using the Inception V3 model. After several experiments, The total of Animal Skin images have an retrieval accuracy of $70 \%$ can be seen in the Figure 4.0.

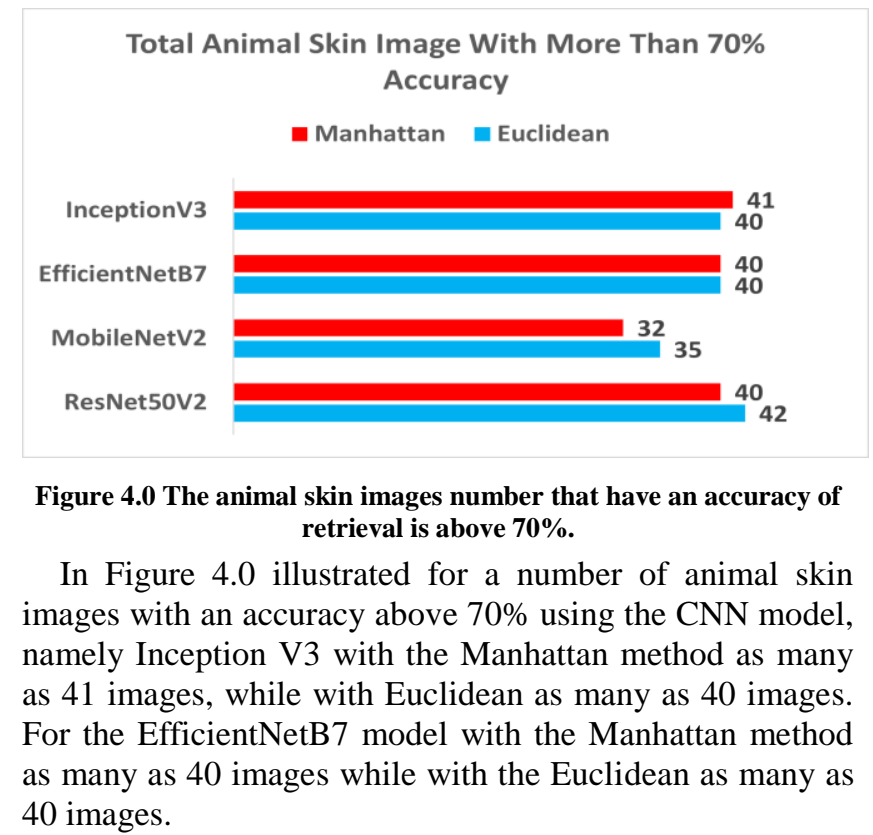




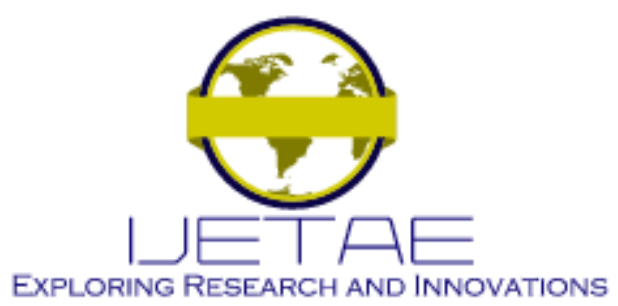

International Journal of Emerging Technology and Advanced Engineering Website: www.ijetae.com (E-ISSN 2250-2459, Scopus Indexed, ISO 9001:2008 Certified Journal, Volume 12, Issue 02, February 2022)

For the Mobilenet V2 model with the Manhattan method as many as 32 images while with Euclidean as many as 35 images. For the Resnet 50V2 model with the Manhattan method as many as 40 images while with the Euclidean as many as 42 images. With this image, it can be concluded that the highest number of images with classification accuracy is above $70 \%$ using the Inception V3 model.

These are the results in the retrieval experiment on animal skin images, the feature extraction process used 4 CNN models and segmentation process use RGB + Equalized. The experiment results of Skin animal image retrieval can be seen in Figure 5.0

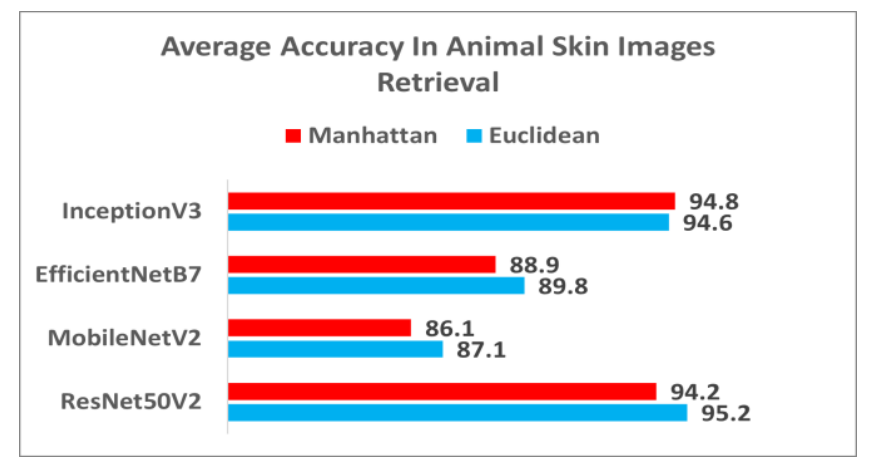

Figure 5.0: Average accuracy of animal skin image retrieval using 4 CNN models

In Figure 5.0, the highest accuracy results in retrieval on animal skin images using the CNN model are Inception V3 with the Manhattan method of $94.8 \%$, while Euclidean is 94.6\%. In the EfficientNetB7 model, the Manhattan method is $88,9 \%$ while the Euclidean method is $89.8 \%$. In the Mobilenet V2 model, the Manhattan method is $86.1 \%$ while the Euclidean method is $87.1 \%$. Resnet $50 \mathrm{~V} 2$ model with Manhattan method is $94.2 \%$ while Euclidean is $95.2 \%$. With this description, it can be concluded that the highest accuracy is using the Inception V3 model.

After several experiments using $4 \mathrm{CNN}$ Model and distance matric, The total of Animal Skin images have an retrieval accuracy of $70 \%$ can be seen in the Figure 6.0.

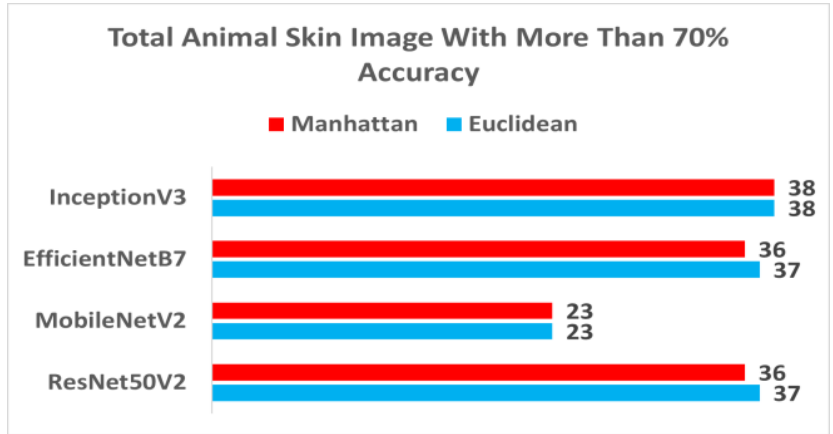

Figure 6.0 The animal skin images number that have an accuracy of retrieval is above $70 \%$.

In Figure 6.0 illustrated for a number of animal skin images with an accuracy above $70 \%$ using the CNN model, namely Inception V3 with the Manhattan method as many as 38 images, while with Euclidean as many as 38 images. For the EfficientNetB7 model with the Manhattan method as many as 36 images while with the Euclidean as many as 37 images. For the Mobilenet V2 model with the Manhattan method as many as 23 images while with Euclidean as many as 23 images. For the Resnet 50V2 model with the Manhattan method as many as 36 images while with the Euclidean as many as 37 images. With this image, it can be concluded that the highest number of images with classification accuracy is above $70 \%$ using the Inception V3 model.

In this experiment, the average retrieval accuracy results where the segmentation process used RGB and Equalized to support the extraction of animal skin image features using $4 \mathrm{CNN}$ models and the Manhattan Distance method for measuring similarity can be seen in Table 1.0.

Tabel 1.0

The average retrieval accuracy using $4 \mathrm{CNN}$ and the Manhattan Distance

\begin{tabular}{|c|c|c|c|c|}
\hline CNN Model & |Mean & Min & Max & Total \\
\hline \multirow[b]{2}{*}{ ResNet5oV2 } & $96 \%$ & $72 \%$ & $100 \%$ & 40 \\
\hline & $94 \%$ & $36 \%$ & $100 \%$ & 36 \\
\hline \multirow{3}{*}{ MobileNetV2 } & $93 \%$ & $72 \%$ & $100 \%$ & 32 \\
\hline & $86 \%$ & $35 \%$ & $100 \%$ & 23 \\
\hline & $96 \%$ & $72 \%$ & $100 \%$ & 40 \\
\hline \multirow[t]{2}{*}{ EfficientNetB7 } & $89 \%^{\circ}$ & $40 \%$ & $100 \%$ & 36 \\
\hline & $97 \%$ & $84 \%$ & $100 \%$ & 41 \\
\hline InceptionV3 & $95 \%$ & $40 \%$ & $100 \%$ & 38 \\
\hline \multirow[t]{3}{*}{ Note: } & & & & \\
\hline & $=\mathrm{RGBO1}$ & & & \\
\hline & $=$ Equalized & & & \\
\hline
\end{tabular}




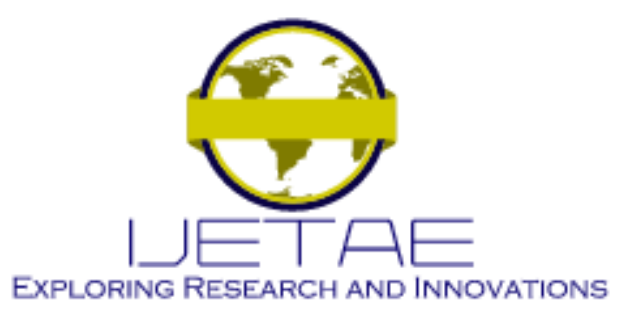

International Journal of Emerging Technology and Advanced Engineering Website: www.ijetae.com (E-ISSN 2250-2459, Scopus Indexed, ISO 9001:2008 Certified Journal, Volume 12, Issue 02, February 2022)

Table 1.0 shows the highest retrieval accuracy is up to $97 \%$ and the number of images whose accuracy is above $70 \%$ reaches 41 images used Inception V3 model. The segmentation method used RGB and Equalied. It is supported by the Manhattans distance in determining the similarity of animal skin images. Furthermore, the highest accuracy reached $96 \%$ with the number of images above $70 \%$ reaching 40 images of animal skins.

Eventually, all of the methods resulted of $100 \%$ maximum accuracy value used Inception V3 Model and Euclidean distance. The accuracy value can be seen on the following top 10 accuracy charts which it can be seen in Figure 7.0.

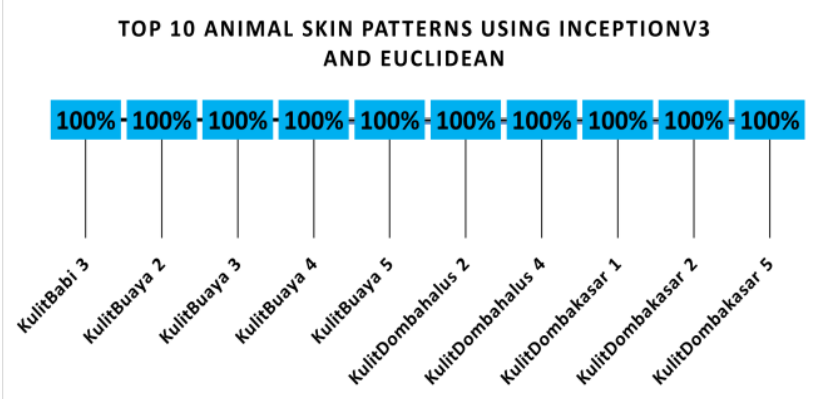

Figure 7.0 Accuracy Results of 10 Skin Animal Imagess with Inception V3 and Euclidean Distance

In Figure 23 shows several images of animal skins that have a retrieval accuracy of $100 \%$. Some animal skins that have $100 \%$ accuracy such as crocodile skin there are 5 kinds, rough sheep skin there are 2 kinds. Crocodile skin has retrieval accuracy because it has very clear texture characteristics compared to other skin images.

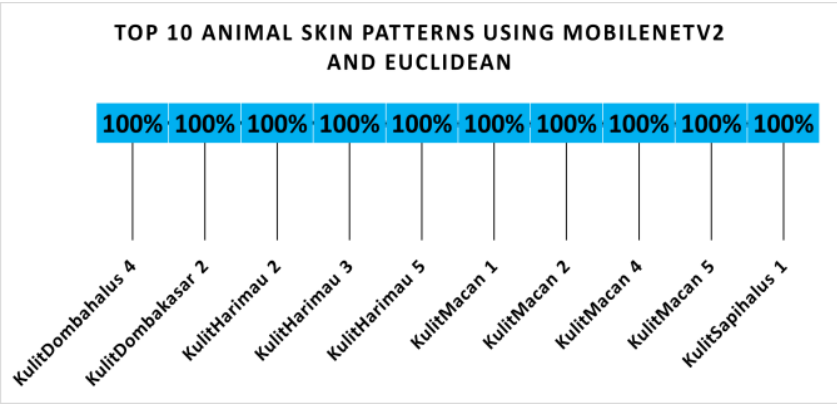

Figure 8.0 Accuracy Results of 10 Skin Animal Imagess with Mobilenet V2 and Euclidean Distance

In Figure 8.0 shows several Images of animal skins that have a retrieval accuracy of $100 \%$. Some animal skins that have $100 \%$ accuracy such as 3 kinds of tiger skins, 4 kinds of tiger skins.
This happens because tiger skin and skin have very clear characteristic textures compared to other skin images so that the accuracy can again reach the optimal level.

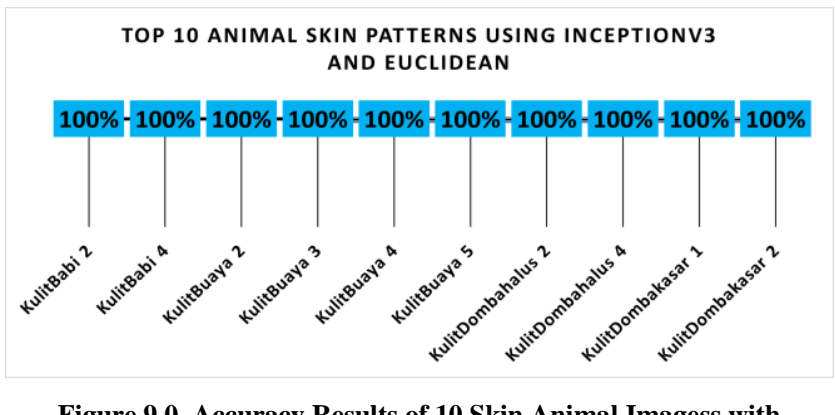

Figure 9.0 Accuracy Results of 10 Skin Animal Imagess with inception V3 and Euclidean Distance

In Figure 9.0 shows several Images of animal skins that have a retrieval accuracy of $100 \%$. Some animal skins that have $100 \%$ accuracy, such as 5 kinds of crocodile skin, 4 kinds of sheepskin, mattress and smooth skin. This happens because tiger skin and skin have very clear characteristic textures compared to other skin images so that the accuracy can again reach the optimal level.

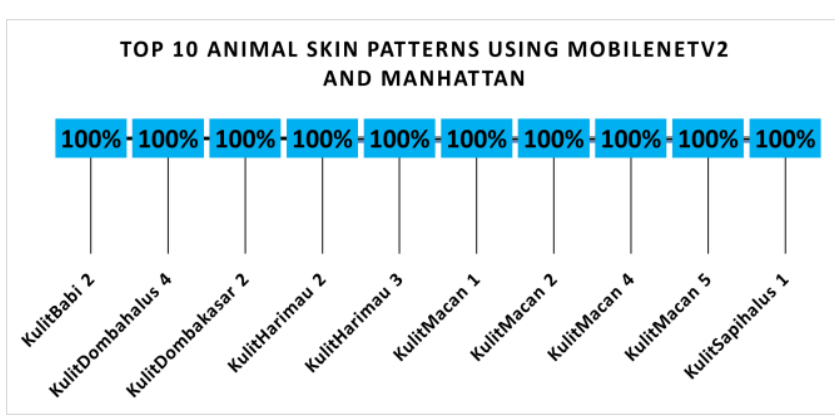

Figure 10.0 Accuracy Results of 10 Skin Animal Imagess with mobilenet V2 and Manhattan Distance

In Figure 10.0 shows several Images of animal skins that have a retrieval accuracy of $100 \%$. Some animal skins that have $100 \%$ accuracy such as tiger skins as much as 4 kinds, tiger skins there are 2 kinds. This happens because tiger skin and skin have very clear characteristic textures compared to other skin images so that the accuracy can again reach the optimal level.

In this experiment, the average retrieval accuracy results where the segmentation process used RGB and Equalized to support the extraction of animal skin image features using $4 \mathrm{CNN}$ models and the Euclidean Distance method for measuring similarity can be seen in Table 2.0. 


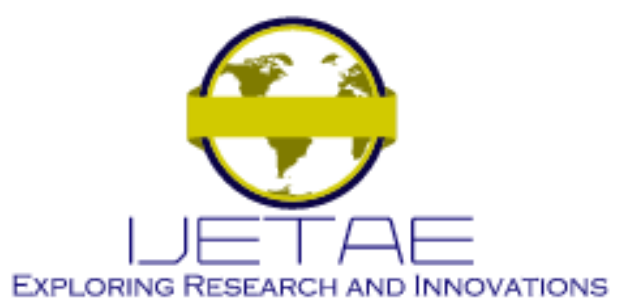

International Journal of Emerging Technology and Advanced Engineering

Website: www.ijetae.com (E-ISSN 2250-2459, Scopus Indexed, ISO 9001:2008 Certified Journal, Volume 12, Issue 02, February 2022)

Tabel 2.0

The average retrieval accuracy using $4 \mathrm{CNN}$ and the Euclidean Distance

\begin{tabular}{|c|c|c|c|c|}
\hline CNN Model & Mean & & $\rrbracket$ Max & |Total \\
\hline \multirow[b]{2}{*}{ ResNet50V2 } & $96 \%$ & $42 \%$ & $100 \%$ & 42 \\
\hline & $95 \%$ & $37 \%$ & $100 \%$ & 37 \\
\hline \multirow{3}{*}{ MobileNetV2 } & $92 \%$ & $35 \%$ & $100 \%$ & 35 \\
\hline & $87 \%$ & $23 \%$ & $100 \%$ & 23 \\
\hline & $96 \%$ & $40 \%$ & $100 \%$ & 40 \\
\hline \multirow[t]{2}{*}{ EfficientNetB7 } & $90 \%$ & $37 \%$ & $100 \%$ & 37 \\
\hline & $97 \%$ & $40 \%$ & $100 \%$ & 40 \\
\hline InceptionV3 & $95 \%$ & $38 \%$ & $100 \%$ & 38 \\
\hline \multirow[t]{3}{*}{ Note: } & & & & \\
\hline & = RGB01 & & & \\
\hline & = Equalized & & & \\
\hline
\end{tabular}

Table 1.0 shows the highest retrieval accuracy is up to 97\% used Inception model and the number of images whose accuracy is above $70 \%$ reaches 42 images used Resnet50V2 model. The segmentation method is RGB, used feature extraction with Inception V3. It is supported by the Euclidean distance in determining the similarity of animal skin images. Furthermore, the highest accuracy reached $96 \%$ with the number of images above $70 \%$ reaching 40 images of animal skins.

In the Accuracy Retrieve process animal skin images by combining the RGB and Equalized methods. The result after carry out the experiment can be seen in figure 11.0

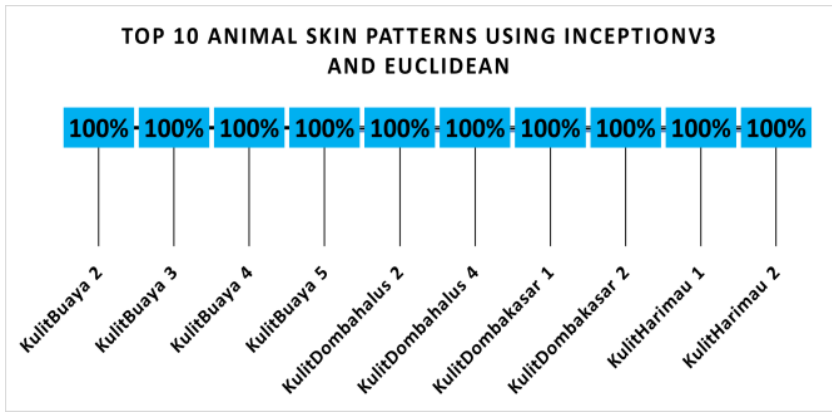

Figure 11.0 Accuracy Results of 10 Skin Animal Images with Inception V2 and Euclidean Distance

Figure 11.0 shows some pictures of animal skins that have a $100 \%$ capture accuracy. Some animal skins that have $100 \%$ accuracy such as crocodile skin as much as 3 kinds, sheep skin there are 4 kinds. This happens because the skin and skin of tigers and sheep have very clear texture characteristics compared to other skin images so that the accuracy can again reach an optimal level.
TOP 10 ANIMAL SKIN PATTERNS USING MOBILENETV2 AND EUCLIDEAN

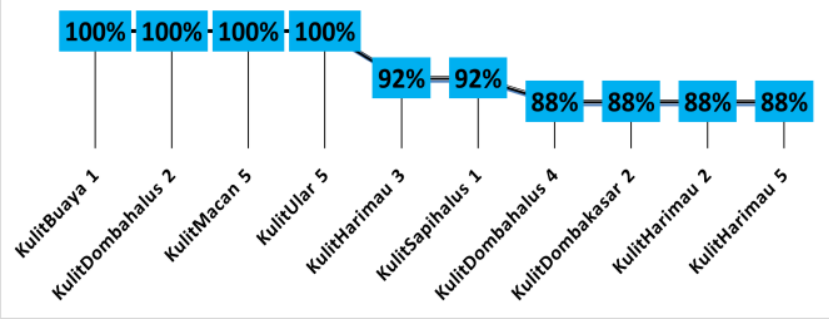

Figure 12.0 Accuracy Results of 10 Skin Animal Imagess with mobile net V2 and Manhattan Distance

Figure 12.0 shows some images of animal skins that have $100 \%$ capture accuracy such as sheepskin, crocodile skin and tiger skin and snake skin. Some animal skins have an accuracy between $92 \%$ and $88 \%$ such as tiger skin and sheep skin.

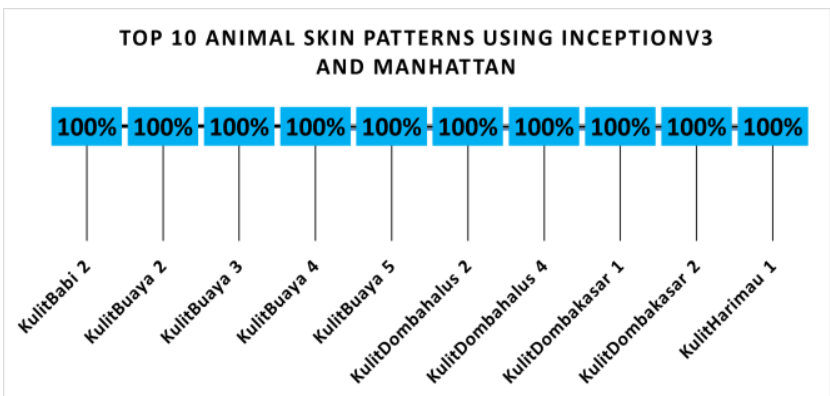

Figure 13.0 Accuracy Results of 10 Skin Animal Imagess with mobile net V2 and Manhattan Distance

Figure 13. 0 shows several Images of animal skins that have a retrieval accuracy of $100 \%$. Some animal skins that have $100 \%$ accuracy such as crocodile skins as much as 4 kinds, sheep skins there are 4 kinds. In this experiment crocodile skin and sheep skin have very clear characteristic textures compared to other skin images so that the accuracy can again reach the optimal level.

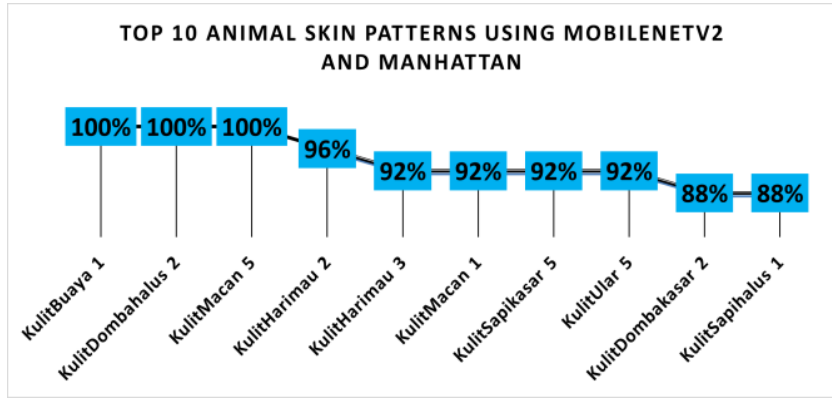

Figure 14.0 Accuracy Results of 10 Skin Animal Imagess with mobile net V2 and Manhattan Distance 


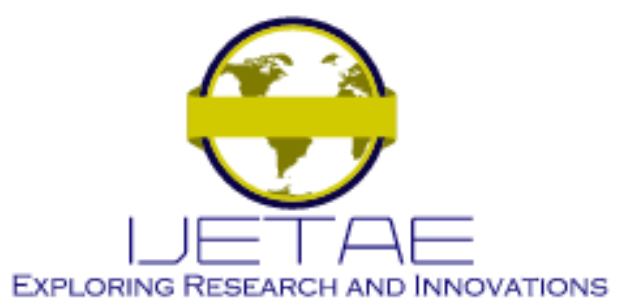

International Journal of Emerging Technology and Advanced Engineering Website: www.ijetae.com (E-ISSN 2250-2459, Scopus Indexed, ISO 9001:2008 Certified Journal, Volume 12, Issue 02, February 2022)

Figure 14.0 shows some images of animal skins that have $100 \%$ capture accuracy such as crocodile skin, sheep skin and tiger skin. Some animal skins have an accuracy between $92 \%$ and $88 \%$ such as coe skin and snake skin. In this experiment inform there are only some animal skin have retrieval accuracy $100 \%$.

\section{CONCLUTION}

1. After doing the experiment Research on the image of animal skins is very difficult to do. This happens because the characteristics of the animal's skin are very delicate and require the right method to get it.

2 . In conducting research on the retrieval of animal skin images using 2 cementation methods which are RGB and RGB equalized. Because with several experiments with several tigers, the segmentation method is not very suitable because the retrieval accuracy is below $50 \%$. However, by using equalized RGB and RGB segmentation, the accuracy of some images can be more than $70 \%$.

3. Research on animal skin images uses a CNN model consisting of Inception V3, Resnet50V2, Mobilenet V2, and EfficientnetB7. After several experiments, the highest retrieval accuracy was found in the CNN Inception V3 model up to $97 \%$ and Resnet50 V2 up to $96 \%$.

4. After the experiment was carried out the retrieval accuracy on several animal skin images it was $100 \%$. Meanwhile, some animal skin images have the lowest accuracy of retrieval, which can be more than $70 \%$. However, most of those that have the highest retrieval accuracy are crocodile skin, snake skin, tiger skin and lion skin images.

\section{REFERENCES}

[1] Hastutiningrum, Sri. 2009. "Pemanfaatan Limbah Kulit Split Industri Penyamakan Kulit Untuk Glue Dengan Hidrolisis Kolagen.” Teknologi 2

[2] Hidayat, G., 2010. Industri Kulit di Indonesia. Universitas Negeri Yogyakarta
[3] Rustam, H. 2009. "Analisis Daya Saing Produk Kulit Olahan Pada Industri Penyamakan Kulit Di Kabupaten Magetan.” MEDIA SOERJO 5 (2).

[4] Nadira, M. (2019). Implementasi deep learning dengan metode convolutional neural network untuk identifikasi citra bahan kulit hewan (Doctoral dissertation, Universitas Pembangunan Nasional Veteran Jakarta).

[5] Purwaningsih, N. (2016). Penerapan Multilayer Perceptron Untuk Temu kembaliJenis Kulit Sapi Tersamak. Jurnal TeknoIf, 4(1).

[6] Purwaningsih, N., \& Jamila, J. (2016). Analisis tekstur kulit sapi berdasarkan ekstraksi ciri citra. Berkala Penelitian Teknologi Kulit, Sepatu, dan Produk Kulit, 15(2), 10-12

[7] Yudha Wijaya, W. (2017). Identifikasi Bahan Jenis Kulit Menggunakan Metode@ DPCA Dan LVQ Pada Citra Digital (Doctoral dissertation, Universitas Komputer Indonesia).

[8] Falcão, L., \& Araújo, M. E. M. (2013). Tannins characterization in historic leathers by complementary analytical techniquesATR-FTIR, UV-Vis and chemical tests. Journal of Cultural Heritage, 14(6), 499508.

[9] Hashim, S. A. M., Jamaluddin, N., \& Hasbullah, A. (2017). Automatic classification of animal skin for leather products using backpropagation neural network. In 4th National Conference On Research And Education.

[10] M. Sarker, "Content-based Image Retrieval Using Haar Wavelet Transform and Color Moment," Smart Comput. Rev., vol. 3, no. 3, 2013, doi: 10.6029/smartcr.2013.03.002.

[11] Rangkuti, A. H., Athala, V. H., Luthfi, N. F., Aditama, S. V., \& Kerta, J. M. (2021, September). Reliable of traditional cloth pattern Classification Using Convolutional Neural Network. In 2021 2nd International Conference on Artificial Intelligence and Data Sciences (AiDAS) (pp. 1-6). IEEE.

[12] A. Anton, N. F. Nissa, A. Janiati, N. Cahya, and P. Astuti, "Application of Deep Learning Using Convolutional Neural Network (CNN) Method For Women's Skin Classification,” Sci. J. Informatics, vol. 8, no. 1, pp. 144-153, 2021, doi: 10.15294/sji.v8i1.26888.

[13] H. S. Ibrahim, M. Si, U. N. Wisesty, F. Informatika, and U. Telkom, "Analisis Deep Learning Untuk Mengenali Qrs Kompleks Pada Sinyal Ecg Dengan Metode Cnn," e-Proceeding Eng., vol. 5, no. 2, pp. 3718-3725, 2018.

[14] S. Sergyán, "Color histogram features based image classification in content-based image retrieval systems," SAMI 2008 6th Int. Symp. Appl. Mach. Intell. Informatics - Proc., no. February, pp. 221-224, 2008, doi: 10.1109/SAMI.2008.4469170 